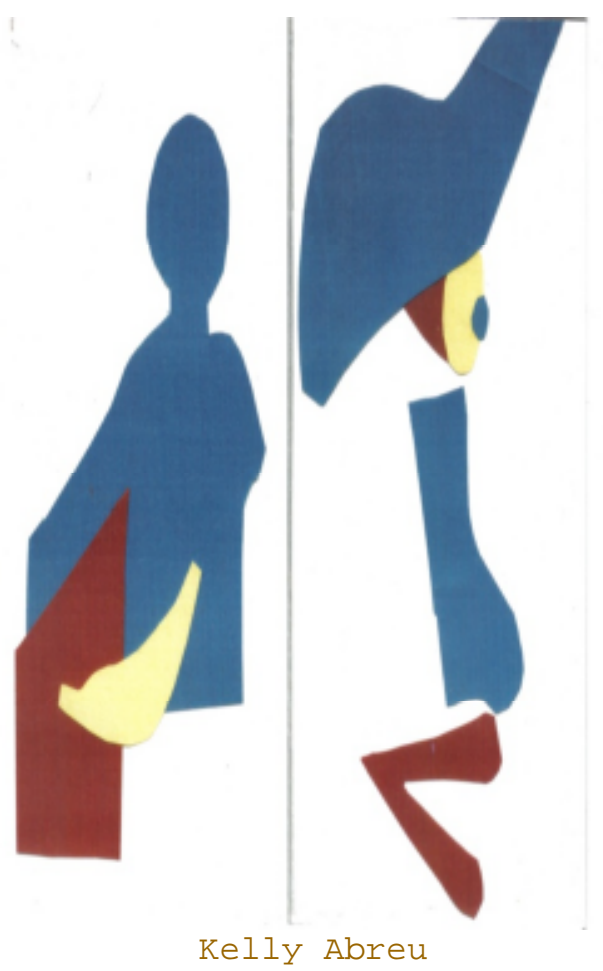

\title{
A literatura, a crítica, a cena cultural: um diálogo com as novas tecnologias
}

\section{Ângela Maria Bedeschi Faria}

Graduada em Letras e Mestre em Estudos Literários pela FALE/UFMG.

\section{Resumo}

Este artigo reflete sobre alguns aspectos decorrentes das transformações ocorridas na esfera literária a partir do descentramento do discurso hegemônico; aborda a prática intertextual, a ampliação do conceito de texto e a apropriação das novas tecnologias.

Palavras-chave: literatura, intertextualidade, novas tecnologias. 
As transformações ocorridas no âmbito das Ciências Humanas, no século $\mathrm{XX}$, decorrentes da descoberta do inconsciente, do descentramento do sujeito, do apagamento da noção de origem e de autoria e da quebra de hierarquia de valores resultaram na crise da epistemologia tradicional. Os chamados discursos das minorias, tidos como marginais, puderam, a partir de então, garantir seu espaço. Nesse panorama de tensão e diluição de fronteiras, fez-se imperativa a revisão dos princípios filosóficos, dos paradigmas relativos ao ensino das ciências, da arte, da literatura e da crítica. No debate entabulado em torno dessas questões, ganha destaque a atitude inquieta de pensadores como Jacques Derrida, Gilles Deleuze, Felix Guattari, Michel Foucault, Jean-François Lyotard, Roland Barthes e outros, que ensejaram a captura de contradições nos sistemas já instituídos, investindo contra a ordem do logos, estruturada em pares opositivos, e do sentido tomado como verdade.

A quebra dos limites dos campos disciplinares e o fomento de um trânsito permanente entre a filosofia, as artes e as ciências permitiram a relativização de valores. Nos diversos segmentos da cultura, o estabelecimento dessas relações apontam para novas direções do saber, convocando, no caso específico da literatura, o escritor e o leitor a lidar de outras formas com os textos e as imagens. A essa altura, visualiza-se a probabilidade de se incorrer na apropriação e na recriação de objetos artísticos em virtude da ampliação do conceito de texto. Tal operação os leva a pensar no percurso labiríntico da literatura, o qual evoca a imagem do conto borgiano "A biblioteca de Babel" (1) .

- espaço dessa biblioteca, configurado em galerias, pressupunha uma organização que se estendia das estantes à forma como nelas os livros se encontravam dispostos. Porém, não seriam apenas esses aspectos a determiná-la. O narrador indicava medidas exatas ao esquadrinhar aquele quadrilátero, tentando convencer o leitor de tal possibilidade. A propósito, sua insistência resvalava para a ironia quando, por meio de suas justificativas, suscitava dúvidas no leitor, as quais o conduziriam ao questionamento da suposta ordem de um espaço que mais se assemelhava a um labirinto.

$\mathrm{Na}$ biblioteca instaura-se a disseminação de sentidos, a começar pelo espaço da obra, do texto propriamente dito, aberto à reescrita permanente. Onde estaria a pretensa ordem nesse vigoroso fluxo de leituras e apropriações? Metáforas, citações, paródia, rearranjo de fragmentos, tradução, simulacro convertendo-se em diferença - transgressão que enseja uma antropofagia literária. O improviso ocorre nas fendas, nos substratos, nas lacunas deixadas no tecido do texto, portanto inacabado, promissor de novos significados a 
textos já conhecidos. Se, num livro, opera-se a multiplicidade de conteúdos e conceitos de teores literário, filológico, filosófico, científico, histórico e sócio-cultural, assim como de temas relacionados à memória, à alteridade, e à tradição, como lhe precisar um gênero e um lugar seguro? Nesse sentido, não há mais o livro único ou o livro-imagem do mundo, representado em formas eternas, mas sim o livro-rizoma.

O conceito rizoma, adotado por Gilles Deleuze (2), alude à dispersão de sentidos, ao sistema descentrado, não representativo, não configurado em estruturas estanques, mas numa relação transgressiva, feita de conexões e linhas de fuga que entretecem uma rede tal qual a concebe Pierre Lévy: "A rede não tem centro, ou melhor, possui permanentemente diversos centros que são como pontas luminosas perpetuamente móveis, saltando de um nó a outro, trazendo ao redor de si uma ramificação infinita de pequenas raízes, de rizomas (...)" (3).

No tocante à literatura, é sabido que o inter-relacionamento de conteúdos de diferentes épocas não é uma prática nova, tendo em vista sua ocorrência entre as obras universais. O escritor, pelas vias de alusões a outros textos, citações e paródias, concedia ao leitor seu percurso de leitura como bem - demonstrou Machado de Assis. O que acontece no panorama atual é que a intertextualidade se converteu em prática e a retomada de textos alheios, destituída da preocupação de fidelidade, confirma o anulamento da dicotomia original/cópia, de pares opositivos, legitimando o simulacro como produção da diferença. A propósito dessa operação, configura-se a metáfora do canibalismo, uma vez que se efetiva, durante a construção do objeto artístico, a devoração do saber do outro. De acordo com a inferência de alguns teóricos, essa forma de lidar com a literatura, a crítica e a tradução permite um novo olhar sobre a tradição, "livre para devorar as fontes" (4) e para aniquilar com a dependência em relação ao cânone.

Nesse sentido, a partir das transformações ocorridas no contexto literário, cabe-nos refletir sobre dois aspectos:para onde e como se direcionou a crítica, desprovida dos pressupostos institucionalizados. A princípio, reconhece-se que a crise instituída no âmbito das Ciências Humanas é concernente aos procedimentos culturais e ao comportamento da sociedade, então tensionada por inúmeros questionamentos.

Relativamente à nova concepção de texto e à possibilidade de sua reescrita, o escritor tem refletido sobre a própria linguagem, o que implica uma autocrítica. Se antes o crítico se pautava por critérios que lhe facultavam uma leitura baseada em normas, hoje seu vetor deve apontar para outras direções. Há que se voltar para a obra, ciente da necessidade de dialogar com outros textos, adotando a ousadia em 
detrimento da atitude de subserviência perante a criação artística, operando "uma crítica que, dando-se a ler como texto, [dê] também a ler outro texto, de modo mais novo e mais rico do que aquele [que] líamos antes; que fosse só linguagem, conservando uma função de metalinguagem, que inventasse, no outro texto, novos valores" (5).

Retomando o conto borgiano, acima mencionado, verifica-se que, por meio da ficção, Borges questionou os paradigmas culturais, os modelos estabelecidos, as verdades absolutas, a ordem e os valores eternos prognosticados pela epistemologia ocidental. Deu-nos a ver sua postura crítica frente às narrativas que tentaram representar o real como se pudessem abarcá-lo com o estabelecimento de uma relação de causa e efeito. Logo, revelou-se antes pelo contingente, pelo transitório, pela transgressão, pelo fragmento, sugerindo ao leitor, por meio de caminhos labirínticos (invenções, dúvidas), a percepção do caos, que se irrompe na biblioteca - o suposto espaço da ordem.

Quanto à cena cultural, o constante deslocamento de povos póscolonizados para os países da língua que os colonizou e o cruzamento de saberes e bens simbólicos (língua, tradição, conhecimentos, seitas etc.) favoreceram a troca de valores, a construção de um novo sentido de nação e de si próprios, decorrentes do contato com a alteridade. Na busca de interação, - atrito, as negociações e o embaralhamento de identidades resultaram em novas encenações entre os sujeitos. Esse percurso, que se desenha num emaranhado móvel, à feição de uma rede febricitante, pode ser sentido nos dizeres de Arjun Appadurai: "los grupos migran, se reagrupan en nuevos lugares, reconstruyen sus historias y reconfiguran sus proyetos étnicos, lo etno de la etnografia adquire una calidad resbaladiza y no localizada", desenhando uma nova paisagem de identidades de grupo que "desplegados por todo el mundo dejaron de estar firmemente amarrados a un territorio y circunscriptos a ciertos limites espaciales"(6).

Movência em rede, multiplicidade de sentidos, interseções, cruzamentos de concepções, linguagens, saberes e informações mediadas pelas novas tecnologias, traduzem um mundo em transmutação. Diante desses pressupostos, tanto o escritor quanto o crítico literário enfrentam um desafio no tocante à mudança de parâmetros na esfera literária. Torna-se relevante a investigação de como a mídia impõe novas codificações e procedimentos à cultura literária, tendo em vista a conexão do texto com a imagem e a sonoridade. Conforme acentua Lévy "a cibercultura faz emergir uma nova forma e maneira de agir. O texto dobra-se, redobra-se, divide-se e volta a colar-se pelas pontas e fragmentos: transmuta-se em hipertexto, e os hipertextos conectam-se para formar o plano hipertextual." (7) 
Transformar o texto em um espetáculo já se tornou uma prática, que se viabiliza sob a forma de eventos literários, entrevistas, shows, poesias sonoras, cerimônias de premiação, peças teatrais e outros.

Lévy ainda afirma que em nossa era das mídias eletrônicas, os sistemas culturais têm múltiplos centros de normatização e escalas de valores diversificados. Essa presença é legitimada por grandes instituições culturais: o sistema educacional vigente, que não lida mais exclusivamente com produtos da alta literatura, e as novas tecnologias, que têm como alvo um público heterogêneo. Com o fenômeno da digitalização e a interiorização da mídia na percepção humana, os recursos ampliam-se. Assim, ele ressalta:

O hipertexto ou a multimídia interativa adequam-se particularmente aos usos educativos. É bem conhecido o papel fundamental do envolvimento pessoal do aluno no processo de ensino-aprendizagem. Quanto mais ativamente uma pessoa participar da aquisição de um conhecimento, mais ela irá integrar-se e reter aquilo que aprender. Ora, a multimídia interativa, graças à sua dimensão reticular ou não linear, favorece uma atitude exploratória, ou mesmo lúdica, face ao material a ser assimilado. É, portanto, um instrumento bem adaptado a uma pedagogia ativa.

O leitor, num lapso de segundo, vê-se diante de uma tela que lhe faculta o acesso a um universo diversificado de conteúdos, consubstanciado de propagandas, serviços, notícias, produções artísticas, chats, jogos virtuais, ensino à distância e outros. o contato com grupos de diferentes nacionalidades e culturas viabiliza parcerias e trocas de experiências.

Cientes da vital importância da informação em nosso mundo, a apropriação das novas tecnologias tornou-se um recurso a mais para a aquisição de conhecimento, o que não implica a invalidação das formas tradicionais no processo de aprendizagem. Os recursos já disponíveis como o CD-ROM, O DVD, - scanner, o pen drive, a câmera digital e outros suportes diversificam as possibilidades de captação do saber, tornando mais dinâmico o nosso viver.

Nesse sentido, a partir dessa avalanche de textos e imagens, não nos compete apenas a mera seleção de conteúdos, tendo em vista a superfluidez já instaurada no ciberespaço. Cabe-nos, portanto, atentar para a perda de discernimento decorrente da velocidade de informações, como nos adverte Beatriz Sarlo em sua obra Cenas da vida pós-moderna. O desenvolvimento da capacidade crítica e da lucidez perante uma nova mentalidade que se forma são operadores indispensáveis nessa construção. 


\section{Resumen}

Esto artículo reflexiona acerca de algunos aspectos oriundos de las transformaciones ocurridas en la esfera literaria, a partir de la descentralización del discurso hegemónico; aborda la práctica intertextual; la ampliación del concepto del texto y la apropiación de las nuevas tecnologías.

Palabras-clave: literatura, intertextualidad, nuevas tecnologías

\section{Notas}

(1) BORGES, 1956.

(2) DELEUZE, 1996.

(3) LÉVY, 1996.

(4) SILVA, 2003.

(5) MOISÉS, 1978.

(6) APPADURAI, 1992.

(7) LÉVY, 1999.

\section{Bibliografia}

APPADURAI, Arjun. La modernidad desbordada. Tradução: Gustavo Remedi. México: Ediciones Trilce, Fondo de Cultura Econômica, 1992.

BORGES, Jorge Luis. Ficciones. Buenos Aires: EMECE, 1956.

DELEUZE, Gilles e GUAtTARI, Félix. Rizoma: introdución. 2. ed. México: Ediciones Coyoacan, 1996.

LÉVY, Pierre.Cibercultura. Tradução: Carlos Irineu da Costa. São Paulo: Editora 34, 1999.

- As tecnologias da inteligência: o futuro do pensamento na era da informática. Tradução: Carlos Irineu da Costa. São Paulo: Editora 34, 1996.

MOISÉS, Leyla Perrone. Texto, crítica, escritura. São Paulo: Ática, 1978. SILVA, Sérgio Antônio. Torres de papel. Sete Lagoas: Maestria, 2003. 